\title{
Thermal properties of wooden based flask from tropical hardwood species
}

\author{
O. Y. OGUNSANWO, I. ONAKPOMA, M. KOREDE \\ Department of Forest Production and Products, University of Ibadan. 200284 Ibadan, Nigeria. `email: ighokpoma@yahoo.com.
}

Manuscript received: 20 April 2020. Revision accepted: 11 June 2020.

\begin{abstract}
Ogunsanwo OY, Onakpoma I, Korede M. 2020. Thermal properties of wooden based flask from tropical hardwood species. Asian J For 4: 61-64. Most materials used for production of conventional thermos flask (metals and plastics) are not environment friendly with particular concerns about plastic which are not biodegradable. Wood waste management is important towards producing environmentally friendly materials and achieving sustainable development in the forestry through the wood waste utilisation as thermos flask. This study was therefore conducted to investigate the thermal properties of wooden thermos flask (WTF) using tropical hardwood species with a view to promoting the use of greener technology. Offcuts of Tectona grandis and Albizia saman were used to produce 12 WTF of two thicknesses (11 mm and $12 \mathrm{~mm}$ ), with a height of 10.5 " using bamboo as inner lining. The heat loss and heat gain by the wooden flasks and conventional flask were collected using a thermometer which was inserted into the cap of the flasks through a hole drilled in it, the hole was covered at intervals to prevent heat loss and heat gain from the opening. Data was collected every two hours for twelve hours. The study was laid out in a $2 \times 2$ factorial experimental in a completely randomized design. Data was analysed using ANOVA at $\mathrm{p}=0.05$. The highest heat loss $\left(64.00^{\circ} \mathrm{C}\right)$ after 12 hours was observed in Tectona grandis WTF with $11 \mathrm{~mm}$ and $12 \mathrm{~mm}$ while Albizia saman thermos flask with $12 \mathrm{~mm}$ thickness had the least heat loss $\left(62.00^{\circ} \mathrm{C}\right)$. Metallic flask lost only about $30.00^{\circ} \mathrm{C}$ of its heat content after 12 hours. The highest heat gain $\left(28^{\circ} \mathrm{C}\right)$ after 12 hours was observed in Tectona grandis WTF with $11 \mathrm{~mm}$ and $12 \mathrm{~mm}$ while Albizia saman WTF with $11 \mathrm{~mm}$ thickness had the least heat gain $\left(25.67^{\circ} \mathrm{C}\right)$. Heat gained by WTF was $28.00^{\circ} \mathrm{C}$ and $25.83^{\circ} \mathrm{C}$ for Tectona grandis and Albizia saman respectively after 12 hours while heat gain by the metallic flask after 12 hours was $18.00^{\circ} \mathrm{C}$. Species and thickness did not significantly affect heat loss and gain of thermos flask. Significant difference was however observed between the heat lost and gained by WTF and metallic flask. Wooden thermos flask still retained heat and prevented loss to a certain degree but with technological improvement would perform better.
\end{abstract}

Keywords: Albizia salman, heat gain, heat loss, Tectona grandis, thermos flask

\section{INTRODUCTION}

When there is a temperature difference between two objects, heat transfer can occur. There are basically three methods of heat transfer namely Conduction (transfer of heat by direct physical contact where molecules in object at higher temperature have higher average kinetic energy and vice versa resulting in energy transfer from former to latter), Convection (transfer of heat by mass movement of fluid (liquid or gas) and occurs when fluid is unevenly heated.), and radiation (heat transfer via the emission or absorption of electromagnetic radiation (e.g. visible light, infra-red, microwaves etc. which possess the ability to travel and carry energy through empty space. All objects emit radiation. At ordinary temperatures this radiation is mainly at infrared wavelengths). In general all three processes occur simultaneously.

Thermal insulation can be defined as the reduction to the flow of heat. Factors affecting the insulation performance are- Thermal conductivity, Surface emissivity, Insulation thickness, Density, Specific heat capacity, etc. (Jatin and Shubham 2015). Over the years, different materials have been used as thermal insulators based on their thermal insulation properties, availability, cost, density and environmental friendliness. Hence, material with low value of thermal conductivity comparable with existing industrial insulator is of global interest. Commonly used materials as thermal insulator include calcium silicate, mineral fibre, fibre glass, Polyurethane, polystyrene, plastic foam etc. Natural products and industrial waste such as cotton wool, clay, sawdust, rice husk among others found to exhibit low thermal conductivity values are also useful as solar device materials. Due to serious environmental degradation caused by industrial activities and the need to conserve energy and resources, various research efforts had been focused towards the utilization of industrial waste around the world (Sumrerng and Prinya 2010). Various attempts are on-going to develop locally available materials with suitable structural and energy conserving properties.

Materials used for production of conventional thermos flask (metals and plastics) are not environment friendly (Palm 2018). Plastic pollution arises from both terrestrial and marine sources which is of particular concern in developing countries that lack proper waste management policies (Thevenon and James 2014; Hayden et al. 2012). In 2012, 165 million tons of plastic polluted the ocean (Reddy et al. 2014). Very little plastic discarded in Nigeria are recycled, much of it ends up in landfills, which may take up to one thousand years to decompose, leaching potentially toxic substances into the soil and water (UN Environment 2018). Also, Iron (Fe) and aluminium ( $\mathrm{Al}$ ) can alter the biodegradation of dissolved organic matter 
(DOM) by forming strong complexes with carboxylic and phenolic groups which are abundant in dissolved organic matter (Xiao et al. 2016).

Wood waste management is important towards achieving sustainable development in the forestry sub sector (Marinela 2009). A major problem with the use of wood is the generation and non-utilization of wood waste such as offcuts, bark, crooked logs, slabs etc. Less than two third of the harvested tree during logging operation are taken from the forest and less than $40 \%$ of the wood gotten from the forest are being converted to lumber in the industrial level leading to an unsustainable utilization of wood which is a setback to the sustainable management of the forest and forest industries (Ogunwusi 2014). Waste generation from wood processing creates a lot of environmental challenges (Ogunbode et al. 2013). The prominent waste disposal methods in Nigeria are burning, dumping, recycling and composting. The predominant wood waste management being open incineration, which leads to release of greenhouse gases and also air pollution. It is therefore important that ways of recycling these waste are developed, to ensure that wood is sustainably. The use of wood waste on the industrial level has led to the innovation of wood utilization as floor tiles, wall tiles, ceiling boards and laminated wood product (flower vase, trays, lamp holder, etc.) (Ogunsanwo 2001). This could also be extended to other products as thermos flask.

This study was therefore conducted to investigate the thermal properties of wooden thermos flask using tropical hardwood species and comparing between the insulating properties of metallic thermos flasks.

\section{MATERIALS AND METHODS}

\section{Study area}

This study was conducted at the Department of Forest Production and Products wood workshop, University of Ibadan, Ibadan, Oyo State, Nigeria.

\section{Sourcing of materials}

Offcuts of Tectona grandis and Albizia saman were obtained from the Department of Forest Production and Products, University of Ibadan, Nigeria. The wood was then taken to the wood workshop for further processing into thermos flask.

\section{Design of thermos flask}

Twelve thermos flask of two thicknesses $(11 \mathrm{~mm}$ and $12 \mathrm{~mm}$ ), with a height of 10.5 inches were produced using bamboo was used as an inner lining.

\section{Production of thermos flask}

\section{Processing of the wood}

The offcuts were processed into cants using the wood mizer machine and further sawn into rectangular blocks of 14 inches each using a saw. The rectangular blocks were converted to a cylindrical shape. Then partitioned into base and top (cap). The inner and outer part of each sections were turned and sanded.

\section{Preparation of bamboo}

The bamboo was cut into sections, ensuring that they are cut a little below the nodes to have a closed end cylinder. It was steamed using the autoclave at $100^{\circ} \mathrm{C}$ to stabilize it. The inner and outer part were sanded to ensure that the bamboo fits into the already prepared wood. It was then coated with kerosene, as a form of preservation.

\section{Gluing and finishing}

Adhesive was applied to the outside of the bamboo and inside of the carved wood. The bamboo was then placed into the carved wood. Heavy rectangular blocks were then placed on the flask to ensure proper alignment and proper drying of the wood and bamboo. The wooden thermos flask was allowed to dry for three days. An electric sanding machine was used to smoothen the flask and then it was sprayed with paint.

\section{Data collection}

The heat loss and heat gain by the wooden flasks and conventional flask were collected using a thermometer which was inserted into the cap of the flasks through a hole drilled in it, the hole was covered at intervals to prevent heat loss and heat gain from the opening, data was collected every two hours for twelve hours.

\section{Heat loss experiment}

$1000 \mathrm{~mL}$ of hot water at $100^{\circ} \mathrm{C}$ was poured into the flask. The heat loss by the wooden flasks and metallic flask were collected using a thermometer which was inserted into the cap of the flasks through a hole drilled in it, the hole was covered with cotton wool to prevent heat loss through the opening. The temperature was measured and recorded every two hours for twelve hours

\section{Heat gain experiment}

$1000 \mathrm{~mL}$ of iced water at $0^{\circ} \mathrm{C}$ was poured into the flask. The heat gain by the wooden flasks and metallic flask were collected using a thermometer which was inserted into the cap of the flasks through a hole drilled in it, the hole was covered with cotton wool to prevent heat gain through the opening. The temperature was measured and recorded every two hours for twelve hours for calculation of heat gain.

\section{Experimental design and data analysis}

The study design is a $2 \times 2$ factorial experimental design in a completely randomized design with thickness $(11 \mathrm{~mm}$ and $12 \mathrm{~mm}$ ) and species (Tectona grandis and Albizia saman) as factors. Data was analysed using ANOVA at $\mathrm{p}=0.05$.

\section{RESULTS AND DISCUSSION}

\section{Heat loss}

Table 1 shows the mean heat loss of Tectona grandis and Albizia saman wooden thermos flask (Figure 1) with varying thickness. The highest heat loss $\left(64.00^{\circ} \mathrm{C}\right)$ after 12 hours was observed in Tectona grandis wooden thermos flask with $11 \mathrm{~mm}$ and $12 \mathrm{~mm}$ while Albizia saman thermos flask with $12 \mathrm{~mm}$ thickness had the least heat loss 
$\left(62.00^{\circ} \mathrm{C}\right)$. The was a sharp drop in wooden flask temperatures for both wood species for the first two hours while the temperature stabled after 10 hours of filling. The heat loss reduces with time at varying interval. Species and thickness did not significantly affect heat gain of thermos flask as shown in the table.

In Table 2, it was observed that the heat loss was greater in both wooden flasks when compared with that of a metallic flask. Metallic flask lost only about $30.00{ }^{\circ} \mathrm{C}$ of its heat content while Tectona grandis and Albizia saman lost $64.00^{\circ} \mathrm{C}$ and $62.17^{\circ} \mathrm{C}$ of its heat content after 12 hours which doubles that lost by metallic flask. Also significant difference was also observed between the wooden flasks and metallic flask.

\section{Heat gain}

Table 3 shows the mean heat gain of Tectona grandis and Albizia saman wooden thermos flask with varying thickness. The highest heat gain $\left(28^{\circ} \mathrm{C}\right)$ after 12 hours was observed in Tectona grandis wooden thermos flask with 11 $\mathrm{mm}$ and $12 \mathrm{~mm}$ while Albizia saman thermos flask with 11 $\mathrm{mm}$ thickness had the least heat gain $\left(25.67^{\circ} \mathrm{C}\right)$. The temperature of water in the wooden thermos flask was observed to be stable after 10 hours of filling. The heat loss reduces with time at varying interval. Species and thickness did not significantly affect heat gain of thermos flask as also represented in the table

The heat was gained faster in the wooden flasks than that of a metallic flask. Heat gained by wooden flask was $28.00^{\circ} \mathrm{C}$ and $25.83^{\circ} \mathrm{C}$ for Tectona grandis and Albizia saman respectively after 12 hours while heat gain by the metallic flask after 12 hours was $18.00^{\circ} \mathrm{C}$ (Table 4). Significant difference was also observed between the heat gained by wooden flasks and metallic flask.

\section{Discussion}

The highest heat gain and loss for wooden flask was obtained from the first two hours and the lowest mean value was obtained from the last two hours for both thicknesses, which means that the wooden flask lost heat at a fast rate for the first two hours. This could be due to the absence of a lagging material such as cotton wool or silver panel used for metallic flask that helps to trap heat in the flask thus reducing heat loss and gain by the flask. The loss of energy is in line with the second law of thermodynamics which states that "in all energy exchanges if no energy enters or leaves the system, the potential energy of the state will always be less than that of the initial state". Also the temperature for the last two hours was constant which also in in line with Newton's law of cooling which states that the "the rate of change in the temperature of an object is proportional to the difference between its own temperature and the ambient temperature". This therefore infers that the temperature was constant due to the fact that the temperature of the water, flask and its surroundings were at an equilibrium temperature.

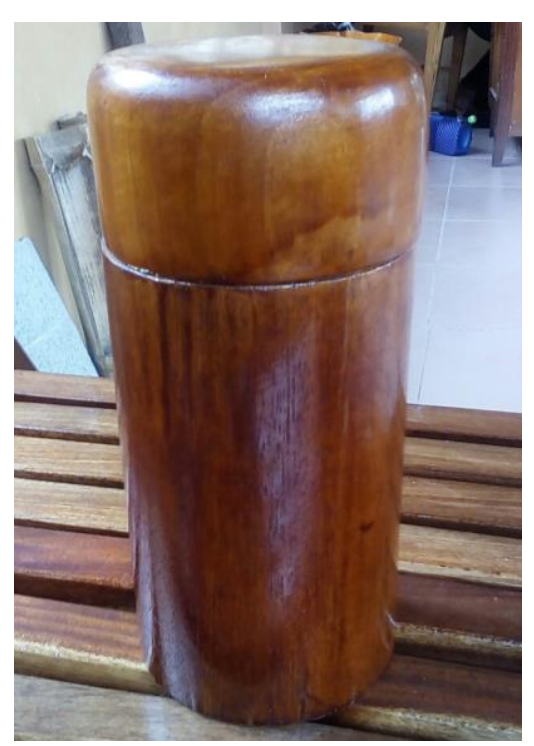

Figure 1. Wooden thermos flask

Table 1. Mean values of heat loss of Tectona grandis and Albizia saman with varying thickness

\begin{tabular}{|c|c|c|c|c|c|}
\hline \multirow{2}{*}{ Time } & Species & \multicolumn{2}{|c|}{ Tectona grandis } & \multicolumn{2}{|c|}{ Albizia saman } \\
\hline & Thickness & $11 \mathrm{~mm}$ & $12 \mathrm{~mm}$ & $11 \mathrm{~mm}$ & $12 \mathrm{~mm}$ \\
\hline Initial & & 100.00 & 100.00 & 100.00 & 100.00 \\
\hline 2 hours & & $76.33 \pm 0.44$ & $76.00 \pm 0.44$ & $85.00 \pm 0.44$ & $85 \pm 0.44$ \\
\hline 4 hours & & $62.00 \pm 0.69$ & $61.33 \pm 0.69$ & $69.33 \pm 0.69$ & $69.00 \pm 0.69$ \\
\hline 6 hours & & $51.33 \pm 0.60$ & $52.00 \pm 0.60$ & $60.00 \pm 0.60$ & $59.00 \pm 0.60$ \\
\hline 8 hours & & $40.67 \pm 0.60$ & $41.00 \pm 0.60$ & $50.00 \pm 0.60$ & $50.00 \pm 0.60$ \\
\hline 10 hours & & $36.00 \pm 0.17$ & $36.00 \pm 0.17$ & $40.33 \pm 0.17$ & $40.33 \pm 0.17$ \\
\hline 12 hours & & $36.00 \pm 0.17$ & $36.00 \pm 0.17$ & $37.67 \pm 0.17$ & $38.00 \pm 0.17$ \\
\hline Heat loss & & 64.00 & 64.00 & 62.33 & 62.00 \\
\hline
\end{tabular}

Table 2. Heat loss of Tectona grandis and Albizia saman and metallic flask

\begin{tabular}{|c|c|c|c|c|c|c|c|c|}
\hline & $\begin{array}{c}\text { Initial } \\
\left({ }^{\circ} \mathrm{C}\right)\end{array}$ & $\begin{array}{l}2 \mathrm{hrs} \\
\left({ }^{\circ} \mathrm{C}\right)\end{array}$ & $\begin{array}{l}4 \mathrm{hrs} \\
\left({ }^{\circ} \mathrm{C}\right)\end{array}$ & $\begin{array}{l}6 \text { hrs } \\
\left({ }^{\circ} \mathrm{C}\right)\end{array}$ & $\begin{array}{c}8 \text { hrs } \\
\left({ }^{\circ} \mathrm{C}\right)\end{array}$ & $\begin{array}{c}10 \text { hrs } \\
\left({ }^{\circ} \mathrm{C}\right)\end{array}$ & $\begin{array}{c}12 \text { hrs } \\
\left({ }^{\circ} \mathrm{C}\right)\end{array}$ & Heat loss \\
\hline T. grandis & 100 & 76.17 & 62 & 51.69 & 40.83 & 36 & 36 & $64.00^{\mathrm{a}}$ \\
\hline A. saman & 100 & 85 & 69.17 & 59.5 & 50 & 40.17 & 37.83 & $62.17^{\mathrm{a}}$ \\
\hline Metallic flask & 100 & 98 & 95 & 86 & 80 & 76 & 70 & $30.00^{\mathrm{b}}$ \\
\hline
\end{tabular}


Table 3. Mean values for heat gain of Albizia saman and Tectona grandis at varying thickness

\begin{tabular}{|c|c|c|c|c|c|}
\hline \multirow{2}{*}{ Time } & \multirow{2}{*}{$\begin{array}{l}\text { Species } \\
\text { Thickness }\end{array}$} & \multicolumn{2}{|c|}{ Tectona grandis } & \multicolumn{2}{|c|}{ Albizia saman } \\
\hline & & $11 \mathrm{~mm}$ & $12 \mathrm{~mm}$ & $11 \mathrm{~mm}$ & $12 \mathrm{~mm}$ \\
\hline Initial & & 0.00 & 0.00 & 0.00 & 0.00 \\
\hline 2 hours & & $12.00 \pm 0.00$ & $12.67 \pm 1.15$ & $7.68 \pm 0.58$ & $7.33 \pm 1.15$ \\
\hline 4 hours & & $20.00 \pm 0.00$ & $20.00 \pm 0.00$ & $15.67 \pm 0.58$ & $15.67 \pm 0.58$ \\
\hline 6 hours & & $24.00 \pm 0.00$ & $24.00 \pm 0.00$ & $19.67 \pm 0.58$ & $20.00 \pm 0.00$ \\
\hline 8 hours & & $26.33 \pm 0.58$ & $26.00 \pm 0.00$ & $24.67 \pm 1.15$ & $24.67 \pm 1.15$ \\
\hline 10 hours & & $28.00 \pm 0.00$ & $28.00 \pm 0.00$ & $26.33 \pm 0.58$ & $24.67 \pm 1.15$ \\
\hline 12 hours & & $28.00 \pm 0.00$ & $28.00 \pm 0.00$ & $25.67 \pm 0.58$ & $26.00 \pm 0.00$ \\
\hline
\end{tabular}

Table 4. Heat gain of Tectona grandis, Albizia saman and metallic flask

\begin{tabular}{lcccccccc}
\hline & $\begin{array}{c}\text { Initial } \\
\left({ }^{\circ} \mathbf{C}\right)\end{array}$ & $\begin{array}{c}\mathbf{2} \text { hrs } \\
\left({ }^{\circ} \mathbf{C}\right)\end{array}$ & $\begin{array}{c}\mathbf{4} \text { hrs } \\
\left({ }^{\circ} \mathbf{C}\right)\end{array}$ & $\begin{array}{c}\mathbf{6} \text { hrs } \\
\left({ }^{\circ} \mathbf{C}\right)\end{array}$ & $\begin{array}{c}\mathbf{8} \text { hrs } \\
\left({ }^{\circ} \mathbf{C}\right)\end{array}$ & $\begin{array}{c}\mathbf{1 0} \text { hrs } \\
\left({ }^{\circ} \mathbf{C}\right)\end{array}$ & $\begin{array}{c}\mathbf{1 2} \mathbf{~ h r s} \\
\left({ }^{\circ} \mathbf{C}\right)\end{array}$ & $\begin{array}{c}\text { Heat } \\
\text { gain }\end{array}$ \\
\hline T. grandis & 0 & 12.33 & 20 & 24 & 26.17 & 28 & 28 & $28.00^{\mathrm{a}}$ \\
A. saman & 0 & 7.5 & 15.67 & 19.83 & 24.67 & 26.17 & 25.83 & $25.83^{\mathrm{a}}$ \\
Metallic flask & 0 & 3 & 6 & 9 & 12 & 14 & 18 & $18.00^{\mathrm{b}}$ \\
\hline
\end{tabular}

Studies has shown that the thermal conductivity of wood is low, has it is within the range of $0.1-0.8 \mathrm{Wm}^{-1} \mathrm{~K}^{-1}$ (Samuel et al. 2012) with teak having a thermal conductivity of $0.139 \mathrm{Wm}^{-1} \mathrm{~K}^{-1}$ (Mohapatra et al. 2014) when compared to materials used to make the metallic flask, this means that the high heat loss and gain could not have been as a result of wood having higher thermal conductivity than this materials but due to increased conduction, convection and radiation in the wooden thermos flask. Oluyamo and Bello, (2014) reported sawdust to also exhibit low thermal conductivity (0.045199-0.147759 $\left.\mathrm{Wm}^{-1} \mathrm{~K}^{-1}\right)$ that is comparable with materials used as insulator in industrial solar flat plate collectors in lagging of refrigerator, incubator, cooler, food flask etc. as well as exhibiting high thermal resistivity value which could serve as potential sources of heat resistant in device applications.

In conclusion, this study has shown that wood residues such as offcuts can be used to produce thermos flask. The result of this research shows variation in the heat loss and gain of Albizia saman and Tectona grandis of varying thickness and species with time. Also, this study shows that wooden thermos flask gained and lost heat faster than conventional flask after 12 hours which may be as a result of the absence of lagging materials in between the wood which would have helped to prevent heat gain and loss by conduction, convection and radiation. However, wooden thermos flask still retained heat and prevented loss to a certain degree. Further research should be carried out on how to improve the wooden thermos flask with respect to heat loss and gain so as to be used as substitute for the plastic and metallic flask.

\section{REFRENCES}

Hayden KW, Arnott J, Crawford RJ, Ivanova EP. 2013. Plastic degradation and its environmental implications with special reference to poly (ethylene terephthalate). Polymer 5: 1-18. DOI: 10.3390/polym5010001

Jatin SA, Shubham NK. 2015. Advancements in Thermos Flask. Intl J Mechan Eng Technol 6 (9): 120-125.

Mohapatra RC, Mishra A, Choudhury BB. 2014. Experimental study on thermal conductivity of teak wood dust reinforced epoxy composite using lee's apparatus method. Intl J Mechanical Eng Appl 2 (6): 98103. DOI: $10.11648 /$ j.ijmea.20140206.13

Marinela B. 2009. The concept of waste management. Analele Universitaii din Oradea. Fascicula: Protectia Mediului 9: 669-673.

Ogunbode EB, Fabunmi FO, Ibrahim SM, Jimoh IO. 2013. Management of sawmill waste in Nigeria: case study of Minna, Niger State. Greener J Sci Eng Technol Res 3 (4): 127-134. DOI: 10.15580/GJSETR.2013.2.012413407

Ogunwusi AA. 2014.Wood waste generation in the forestry industry in Nigeria and prospect for its utilization. Civil Environ Res 6 (9): 6269.

Oluyamo SS, Bello OR. 2014. Particle sizes and thermal insulation properties of some selected wood materials for solar device applications. IOSR J Appl Physics 6 (2): 54-58. DOI: 10.9790/486106215458

Palm K. 2018. How products are made: insulated bottle. http: //www.madehow.com [March 4, 2019]

Reddy MS, Reddy PS, Subbaiah GV, Subbaiah HV. 2014. Effect of plastic pollution on environment. J Chem Pharm Sci 14: 28-29.

Samuel OS, Ramon BO, Johnson YO. 2012. Thermal conductivity of three different wood products of Combretaceae Family; Terminalia superb, Terminalia ivorensis and Quisqualis indica. J Nat Sci Res 2 (4): 36-43.

Sumrerng R, Prinya C. 2010. Strength and carbonation model of rice husk ash cement mortar with different fineness. Mater Civil Eng 2010, 253-259. DOI: 10.1061/(ASCE)0899-1561(2010)22:3(253)

Thevenon F, Oliver J. 2014. Plastic Pollution. Submerge. International Union for Conservation of Nature (IUCN) Global Marine and Polar Programme (GMPP), UK.

UN Environment. 2018. Plastic planet: how tiny plastic particles are polluting the soil. UN environment. http://www.unenvironment.org. [March 5, 2014]

Xiao YH, Hoikkala L, Kasurinen V, Tiirola M, Kortelainen P, Vähätalo AV. 2016. The effect of iron on the biodegradation of natural dissolved organic matter. J Geophys Re Biogeosci 121: 2544-2561. DOI: $10.1002 / 2016 J G 003394$. 